\title{
The Role of Physicians in Rationing Cancer Care. Attitudes of German Oncologists
}

\author{
Sandra Fernau $^{a}$ Katja Mehlis ${ }^{a}$ Jan Schildmann ${ }^{b, c}$ Stefan Krause ${ }^{d}$ Eva C. Winkler ${ }^{a}$ \\ ${ }^{a}$ Department of Medical Oncology, University Hospital Heidelberg, National Center for Tumor Diseases (NCT), Heidelberg, Germany; \\ ${ }^{\mathrm{b}}$ Institute for Ethics, Wilhelm Löhe University of Applied Science, Fürth, Germany; \\ c Department of Medicine III, University Hospital Munich, Campus Großhadern, Munich, Germany; \\ d Department of Internal Medicine 5, Hematology/Oncology, University of Erlangen, Erlangen, Germany
}

\section{Keywords}

Rationing cancer care $\cdot$ Cost-effectiveness .

Withholding beneficial treatment - Role of oncologists .

Quantitative and qualitative data

\section{Summary}

Background: Against the background of limited resources, the rise in the cost of therapy as well as in the number of cancer patients fuels the discussion about the necessity to ration, i.e., setting limits to beneficial treatment for cost reasons. Recently, we presented the selfreported prevalence of bedside rationing among German oncologists. Here, we describe oncologists' views on cost containment strategies and their role therein. Methods: We performed an online survey including structured questions and free field sections with the members of the German Society of Hematology and Oncology. Results: In the perception of oncologists, cost considerations and negotiations are gaining in importance and consume considerable working time. This negatively affects job satisfaction in $72 \%$ of the 345 respondents. Oncologists are concerned that the quality of care will suffer from rationalization and implicit rationing. They are ambivalent as to who is best suited to decide about resource rationing: $66 \%$ support the view that limits for costly procedures should be set by a form of commission; nevertheless, $48 \%$ consider physicians as the best decision makers in these situations. Conclusion: We suggest a broad public discussion and an interdisciplinary debate among the oncology community to define and legitimize decisions on rationing by setting explicit criteria.

(c) 2017 S. Karger GmbH, Freiburg

Sandra Fernau and Katja Mehlis share first authorship; Stefan Krause and Eva C. Winkler share last authorship.

\section{Introduction}

As a consequence of new diagnostic and therapeutic options in cancer treatment and increasing numbers of patients, the medical costs of cancer care have grown considerably in the past 2 decades $[1,2]$. Although innovations in cancer prevention, diagnosis, and treatment improve patients' quality of life and chances for survival, they come at substantial economic costs for healthcare systems, insurers, and society [3]. With regard to strategies for cost containment, 3 main terms are commonly distinguished: rationalization, rationing, and prioritization. While through rationalization existing efficiency reserves are to be exhausted, rationing is commonly understood as withholding beneficial interventions mostly for cost reasons. Prioritization is often a prerequisite for rationing decisions, which means ranking medical treatments according to their importance [4-6].

Many authors and experts maintain that limited financial resources and rising costs make rationing in oncology unavoidable (e.g., $[1,2,4,7])$. Nevertheless, healthcare rationing or the withholding of beneficial interventions is a matter of debate (e.g., [6, $8-10]$ ) since the ethical responsibility of physicians to offer the best available medical care to their patients is in conflict with their role as gatekeepers of limited healthcare resources [11, 12].

The establishment of guidelines on how to tackle the increasingly pressing issue of cost containment in times of rising costs for cancer treatment requires empirical data on how physicians currently handle resource constraints. A review of the international literature indicates that while particularly in the United States much empirical research has been done in the past decades on rationing healthcare in general (e.g., [8-11]), there are few studies with a specific focus on rationing cancer care [13-16]. In Germany, there are hardly any quantitative or qualitative studies available that investigate the attitudes to and determinants of rationing, especially with regard to the oncology sector [17-19]. Thus, in 2011, we conducted an online survey with physician members of the

\section{KARGER}

() 2017 S. Karger GmbH, Freiburg

Fax +497614520714 
Table 1. Attitudes and perceptions towards cost containment

\begin{tabular}{|c|c|c|c|c|c|}
\hline & $\begin{array}{l}\text { I fully agree, } \\
\mathrm{n}(\%)\end{array}$ & $\begin{array}{l}\text { I rather agree, } \\
\mathrm{n}(\%)\end{array}$ & $\begin{array}{l}\text { I rather disagree, } \\
\mathrm{n}(\%)\end{array}$ & $\begin{array}{l}\text { I disagree, } \\
\mathrm{n}(\%)\end{array}$ & $\begin{array}{l}\text { Skip question, } \\
\mathrm{n}(\%)\end{array}$ \\
\hline Stewardship of available resources is a self-evident requirement for me. & $255(74)$ & $84(24)$ & $3(1)$ & $3(1)$ & 0 \\
\hline Dealing with cost issues takes up a large part of my working time. & $67(19)$ & $119(35)$ & $116(34)$ & $43(12)$ & 0 \\
\hline $\begin{array}{l}\text { Cost pressures have affected the satisfaction with my work as a } \\
\text { physician in the last } 5 \text { years. }\end{array}$ & $133(39)$ & $115(33)$ & $66(19)$ & $31(9)$ & 0 \\
\hline $\begin{array}{l}\text { Lower prices for expensive medications have to be negotiated with } \\
\text { pharmaceutical companies, if necessary on a compulsory basis. }\end{array}$ & $165(48)$ & $122(35)$ & $38(11)$ & $16(5)$ & $4(1)$ \\
\hline $\begin{array}{l}\text { In the case of limited resources, it is principally justifiable to withhold } \\
\text { selected medications and measures which are very expensive and } \\
\text { to offer cheaper and slightly less effective alternatives instead. }\end{array}$ & $42(12)$ & $144(42)$ & $79(23)$ & $75(22)$ & $5(1)$ \\
\hline $\begin{array}{l}\text { Decisions to limit medically beneficial treatment should be made } \\
\text { above the physician-patient level, e.g. by a national commission. }\end{array}$ & $108(31)$ & $120(35)$ & $57(17)$ & $54(16)$ & $6(2)$ \\
\hline $\begin{array}{l}\text { If a healthcare system cannot afford to pay for all medical beneficial } \\
\text { services, the physician caring for a respective patient is best } \\
\text { equipped to decide what kind of service a patient should get in the } \\
\text { individual treatment situation. }\end{array}$ & $69(20)$ & $98(28)$ & $83(24)$ & $91(26)$ & $4(2)$ \\
\hline
\end{tabular}

German Society of Hematology and Oncology (DGHO) on how cost pressures were currently affecting their clinical practice. As previously published, although the majority (70\%) of the 345 participating oncologists reported that they withhold therapy because the evidence for costly intervention was not convincing enough, over half of them $(59 \%)$ said that they rationed approved treatments because of an unfavorable cost/benefit calculation [20].

In this article, we present additional quantitative results of this survey among DGHO members and complement these findings with qualitative data from open-ended responses with regard to the following questions: i) What are oncologists' perceptions and strategies in relation to dealing with cost pressures?; ii) Who should decide about withholding beneficial treatment, and how do they see their role in rationing decisions?; and iii) What strategies do respondents suggest for dealing with cost issues in oncology?

\section{Methods}

\section{Questionnaire}

We used a 36-item, self-administered, online questionnaire which covered a broad spectrum of information on different aspects of rationing cancer care. We collected data on i) the prevalence of different rationing strategies; ii) the reasoning against costly treatments; iii) perceived effects of limited resources in general; iv) self-reported knowledge of physicians about the cost-effectiveness of cancer treatments; v) attitudes towards potential approaches to resource restraints; and vi) demographic information. Replies to topics i), ii) and vi) have been previously reported [20], whereas responses to the more subjective topics are presented in this report as descriptive quantitative and qualitative data. In a general open question at the end of the questionnaire, respondents were invited to comment on their experiences with regard to rationing in a free text format. The strategy thereby was to generate more detailed responses in order to gain a deeper understanding of the perspectives of physicians dealing with cancer care rationing. Similarly to other studies, we considered the free text contributions as qualitative data based on the criteria of sufficient length and depth [21-23]. The questions/answers from the questionnaire as well as the statements from the free text sections quoted below are direct translations of the originals and were translated collaboratively by 2 persons in order to minimize subjective bias.
The survey was approved by the ethical committee of the University of Erlangen and meets the standards of the Declaration of Helsinki (2008).

\section{Qualitative Analysis}

The open-ended responses from the free text section were analyzed following the techniques of qualitative content analysis according to Mayring ([24, 25]). The central aim was to structure the content of the statements by extracting notable aspects in an abstracting, summarizing way allowing a systematic comprehension of the data $[25,26]$. For this purpose, all passages were coded and grouped around a few central categories, which were validated internally by intercoder consensus between 4 researchers (E.C.W., J.S., K.M., S.F.).

\section{Results}

Sample

A total of 345 DGHO members participated in the survey; the response rate was $17 \%$. Respondents were predominantly male (83\%) and board certified in hematology and oncology (72\%). Several physicians reported having cared for both inpatients (59\%) as well as outpatients (88\%) in the past 6 months. Most of the respondents were aged between 46 and 55 years (45\%), 36\% were younger than 46 years, and 19\% older than 55 years. 55 (15\%) respondents used the opportunity to comment in the free text sections. The extent of the free text contributions ranged with regard to the number of lines from 1 to 25 with an average of 9 lines. The majority of the respondents commented upon i) their perception of cost pressures and strategies in dealing with related aspects; ii) views on being responsible for rationing decisions; and iii) suggestions regarding strategies for cost containment (table 1).

\section{I) Perceptions and Strategies in Dealing with Cost Pressures}

Almost all survey respondents $(n=339 ; 98 \%)$ stated that stewardship with regard to the available resources is a self-evident requirement (table 1). Interestingly, more than half of the respondents assessed their own knowledge about the cost effectiveness of available measures as only moderate $(n=170 ; 49 \%)$ or low $(n=22$; 
Table 2. Indicated knowledge about effectiveness and cost-effectiveness

\begin{tabular}{lcccc}
\hline & $\begin{array}{l}\text { Low, } \\
\mathrm{n}(\%)\end{array}$ & $\begin{array}{l}\text { Moderate, } \\
\mathrm{n}(\%)\end{array}$ & $\begin{array}{l}\text { High, } \\
\mathrm{n}(\%)\end{array}$ & $\begin{array}{l}\text { Skip question, } \\
\mathrm{n}(\%)\end{array}$ \\
\hline $\begin{array}{c}\text { My knowledge about the effectiveness } \\
\text { of the measures available to me }\end{array}$ & $4(1)$ & $48(14)$ & $287(83)$ & $6(2)$ \\
$\begin{array}{c}\text { My knowledge about the cost-effectiveness } \\
\text { of the measures available to me }\end{array}$ & $22(6)$ & $170(49)$ & $147(43)$ & $6(2)$ \\
\hline
\end{tabular}

10 -point scale from $1=$ very low to $10=$ very high; category building based on: scale values $1-3=$ low, $4-7=$ moderate, $8-10=$ high .
6\%) and thus considerably lower than their perceived knowledge about the effectiveness of the measures (table 2). $54 \%(n=186)$ indicated that dealing with the cost side of treatment consumes a good part of their working time (table 1). In addition, $72 \%$ ( $\mathrm{n}=$ 247) confirmed that within the last 5 years cost pressures have increasingly compromised their satisfaction with their work as a doctor (table 1).

The majority of oncologists $(n=252 ; 73 \%)$ reported that they negotiated reimbursement with third-party payers in situations in which they felt pressured to withhold costly treatments; most of them did so less than once a month $(\mathrm{n}=191 ; 55 \%)$ as previously published [20]. Through qualitative analysis, we can now add that several oncologists are concerned that the delay caused by funding negotiations or the lack of personnel compromises the quality of care:

'In my view, the restrictive legislation concerning the off-label use is also a consequence of resource constraints and results in a deterioration of patient care, only due to the delay of clarifying the cost coverage.'

There are also concerns that withholding indicated measures for financial reasons might be 'hidden' behind medical decisions:

'In the case of therapies that are principally indicated but feared for cost reasons, a medical contraindication is sought to avoid the decision for the expensive therapy that would actually be necessary.'

Respondents also reported that cost containment measures, especially staff reductions due to rationalization procedures, result in uncompensated extra hours because of increased administrative work for the oncologists.

II) Who Should Decide about Withholding Beneficial Treatment? Views on Responsibilities Regarding Rationing

The survey shows that oncologists are ambivalent as to who is best suited to decide about resource rationing: on the one hand, the majority of respondents $(n=228 ; 66 \%)$ agree that decisions to withhold beneficial treatment should be made above the patientdoctor level, for example by a national commission (table 1). On the other hand, almost half of the respondents ( $\mathrm{n}=167 ; 48 \%)$ support the suggestion that the doctor caring for a respective patient would be in the best position to decide about the distribution of treatments in a system that cannot afford to pay for all beneficial treatments (table 1). Analyzing the last two items together, $47 \%$ of respondents are (rather) in favor of decisions above the patientdoctor level, $28 \%$ are in favor of decisions by individual physicians, $21 \%$ support both types of decisions, and 5\% decline any type of decision.
In the free text section, there were also supporting and opposing statements concerning the role of physicians as gatekeepers. The ambivalence is illustrated by the following extract from a physician with an ambiguous opinion, showing intra-individual uncertainties concerning responsibilities for decisions on withholding beneficial treatment:

'Regarding the decision which therapy should be financed, I am divided: On the one hand, I do believe that we as physicians, who are informed about the individual situation and the individual fate, know best which attempts should still be made. On the other hand, we can't always carry the burden of ethical decisions alone.

The following comment argues for physicians as decision makers in resource rationing:

'If not all useful medical services can be financed, the physicians responsible for the individual patient are the best to decide which patient receives which treatment in the individual situation.'

In contrast, some argue that putting physicians in the position to ration based on subjective criteria would lead to injustices since patients who are for example older or less well-informed/less educated would be discriminated against:

'The amount society is willing to pay for medical care has to be defined by a board above the physician-patient level. Otherwise a 2 (more)-tier healthcare system will develop (which is already happening every day) in which the physician decides arbitrarily in accordance with his ethical attitude.'

Many free text respondents made a strong case that politics should set the stage for dealing with scarce resources:

'The political level has to provide a general framework in which medical measures can be restricted without coming into conflict with the patient's rights.'

'It is an imposition by the government that collective ethical issues (...) are resolved on an individual ethical level (...), for example when the physician has to allocate how much treatment the patient is 'worth'.'

\section{III) Suggested Strategies for Cost Containment}

A strong majority of survey respondents $(n=287 ; 83 \%)$ agree that lower prices for expensive medications have to be negotiated with pharmaceutical companies (table 1). Free text comments suggested alternative strategies for cost containment: passing on some of the costs to the insured, financing of phase IV studies by the health insurance companies and sick funds, reduction of administrative and overhead costs (quality management and medical controlling of the sick funds). Evidence-based assessment of the cost- 
benefit ratio of new drugs was a frequently mentioned strategy for cost containment (via prioritization of expensive procedures). A narrow majority of the respondents $(n=186 ; 54 \%)$ accepts the possibility of using a slightly less effective but cheaper treatment for cost reasons (table 1). In the free text sections, some respondents suggested 'marginal effectiveness' as a rationing criterion (benefit argument). Others considered both aspects in a cost-benefit calculation:

'To me, the more interesting discussion is why drugs that show statistically highly significant results (...) but only achieve a few days of prolonged survival and are additionally burdened with high toxicity and monthly therapy costs of $€ 4,000-6,000$ appear in the guidelines without critical appraisal of the proportionality of the measure.'

\section{Discussion}

In Germany, social legislation guarantees that beneficial and cost-effective interventions must not be refused. While rationing is not done explicitly and denied by politicians, some data suggest that implicit rationing takes place in the German healthcare system $[17,18]$. As inpatient and outpatient sectors in Germany are characterized by tight budgets, a discussion about possible rationing, especially for expensive cancer treatments, has started [4, 19]. It is highly controversial whether physicians should have a role in rationing decisions on the micro level. While some say that obviously withholding beneficial interventions is at odds with a physician's obligation to his/her patient's best interests [8], opponents claim that physicians are in the best position to allocate scare resources to their best effect [27].

The present study addresses the lack of research on the role of physicians dealing with cancer care rationing by investigating the experiences and perceptions of oncologists in Germany. We showed earlier that bedside rationing is happening among German oncologists, albeit infrequently and with regard to treatments that are arguably marginally effective [20]. The same applies to other countries in Europe [6] and the United States [9, 10, 13] as other empirical research has demonstrated.

The key findings of our study based on quantitative as well as qualitative data are:

i) Cost considerations and negotiations are gaining in importance and consume more working time in the perception of oncologists. This negatively affects their satisfaction with their work as an oncologist. Our results highlight that the connection between cost pressures and dissatisfaction with work as a physician already pointed out in other studies [18] also applies to the oncological sector. A possible explanation for this finding is that the majority of oncologists see themselves obliged to treat their patients independently of cost considerations. It will be increasingly difficult to adhere to this moral claim with regard to the rising expenses in treatment and care.

ii) Oncologists are concerned that the quality of care will suffer from rationalization measures as well as from implicit rationing. The qualitative data analysis showed oncologists fear that staff shortages as a result of rationalization and treatment delays due to negotiations for funding may threaten the quality of medical ser- vices. Physicians also commented that they react to the perceived cost pressures with cost-benefit considerations based on the individual case. Additionally, more than half of the respondents stated that they rationed approved treatments because of an unfavorable cost-benefit calculation [20]. In line with Strech et al. [7], it can be assumed that the currently prevalent implicit rationing strategies are inconsistent and less transparent and promote unequal treatment. This highlights the need for the development of explicit criteria which are ethically and legally more justifiable.

iii) With regard to their role in allocating resources, oncologists are quite ambivalent, and bedside rationing might lead to role conflicts. The responses to where rationing decisions (if unavoidable) should best be made showed supporting as well as opposing positions to the notion of oncologists adopting the role of gatekeeper. Some of the comments in our study underlined that physicians who are informed about the individual situation are best equipped to decide on treatment. However, a larger part of respondents considered gatekeeping to withhold treatments at odds with their role as advocate of their patients' best interest. This position can be regarded as common in the medical as well as the ethical literature (e. g., $[8,9])$. Thus, an important consequence of cost containment measures and perceived cost pressure is that oncologists experience a role conflict, namely the tension arising from being a patient's advocate while at the same time assuming responsibility for the hospital's or society's limited resources.

The present results emphasize the claim that a broad public discussion and an interdisciplinary debate are required to establish a clearly defined as well as legitimate basis for decisions on rationing and priority setting [19]. Overall, a case can be made that the oncology community is called upon to contribute to the political and societal discourse about setting limits fairly [28]. First steps have already been taken with ASCO (American Society of Clinical Oncology) and ESMO (European Society for Medical Oncology) developing frameworks and criteria for the value-based evaluation of cancer treatments $[29,30]$.

Our study has several limitations. First, the quantitative survey has the shortcoming of a low response rate of $17 \%$ ( $21 \%$ of actively practicing physician members) as is often the case with physiciandirected questionnaires addressing sensitive topics [6,31]. Additionally, only 55 of the 345 respondents used the opportunity to comment in the free text section. This means that the perspectives and views of the participants cannot be considered as representative of all oncologists. The second limitation is that self-reports in the free text section can only capture instances of rationing of which physicians are aware. Third, we can assume that the participants' comments in the free text section were influenced by the previous closed questions of the survey.

\section{Conclusion}

Our findings emphasize that cost pressures leading to rationalization and bedside rationing are profoundly affecting the clinical practice of German oncologists. This underlines that the essential 
question is not whether rationing takes place but how rationing can be performed fairly in order to avoid or minimize significant quality restrictions and to clarify the responsibilities of physicians. In light of medico-ethical considerations, implicit rationing is especially questionable due to the lack of transparency regarding the allocation criteria for scarce resources and the resulting risk of unequal treatment. It is therefore desirable to determine explicit criteria above the physician-patient level, guaranteeing transparency for patients, physicians, and the public based on a broad social agreement. Thereby the demand for fair treatment of the patients would be met, and the physician's dual role as patient advocate and gatekeeper for expensive treatments could be made easier.

\section{Acknowledgment}

The authors wish to thank all members of the German Society of Hematology and Oncology (DGHO) who responded to the questionnaire; the DGHO administration office for logistic support; and the DGHO for funding of the online questionnaire.

\section{Disclosure Statement}

The authors declare that they have no conflicts of interest.

\section{References}

1 Smith TJ, Hillner BE: Bending the cost curve in cancer care. N Engl J Med 2011;364:2060-2065.

2 Elkin EB, Bach PB: Cancer's next frontier: addressing high and increasing costs. Jama 2010;303:1086-1087.

3 Greenberg D, Earle C, Fang CH, Eldar-Lissai A, Neumann PJ: When is cancer care cost-effective? A systematic overview of cost-utility analyses in oncology. J Natl Cancer Inst 2010;102:82-88.

4 Oduncu FS: Priority-setting, rationing and cost-effectiveness in the German health care system. Med Health Care Philos 2013;16:327-339.

5 Winkler E: Rationalisierung, Rationierung, Priorisierung: Terminologie und ethische Begründungsansätze zur Allokation bei begrenzten Ressourcen in der Hämatologie/Onkologie. Oncol Res Treat 2011; 34(suppl 1):2-5.

6 Hurst SA, Slowther AM, Forde R, Pegoraro R, ReiterTheil S, Perrier A, Garrett-Mayer E, Danis M: Prevalence and determinants of physician bedside rationing: data from Europe. J Gen Intern Med 2006;21:1138-1143.

7 Strech D, Synofzik M, Marckmann G: How physicians allocate scarce resources at the bedside: a systematic re view of qualitative studies. J Med Philos 2008;33:80-99.

8 Levinsky NG: The doctor's master. N Engl J Med 1984; 311:1573-1575.

9 Pearson SD: Caring and cost: the challenge for physician advocacy. Ann Intern Med 2000;133:148-153.

10 Cohen $\mathrm{AB}$ : The debate over health care rationing: déjà vu all over again? Inquiry 2012;49:90-100.

11 Weinstein MC: Should physicians be gatekeepers of medical resources? J Med Ethics 2001;27:268-274.

12 Scheunemann LP, White DB: The physician as rationer: uncertainty about the physician's role obligations. Semin Respir Crit Care Med 2012;33:421-426.

13 Sulmasy DP: Cancer care, money, and the value of life whose justice? Which rationality? J Clin Oncol 2007; 25:217-222.
14 Kumar P, Moy B: The cost of cancer care - balancing our duties to patients versus society: are they mutually exclusive? Oncologist 2013;18:347-349.

15 Sulmasy D, Moy B: Debating the oncologist's role in defining the value of cancer care: our duty is to our patients. J Clin Oncol 2014;32:4039-4041.

16 The state of cancer care in America, 2014: a report by the American Society of Clinical Oncology. J Oncol Pract 2014;10:119-142.

17 Schildmann J, Tan J, Vollmann J: (Economical aspects in clinical practice: results from an explorative interview study on the perspectives of oncologists in Germany and England). Onkologie 2011;34(suppl 1):20-24.

18 Strech D, Danis M, Lob M, Marckmann G: (Extent and impact of bedside rationing in German hospitals: results of a representative survey among physicians). Dtsch Med Wochenschr 2009; 134:1261-1266.

19 Lange J, Gonner C, Vollmann J, Rauprich O: (Rationing in German health care with particular consideration of oncology: view points of German stakeholders - a qualitative interview study). Gesundheitswesen 2015;77:8-15.

20 Krause SW, Schildmann J, Lotze C, Winkler EC: Rationing cancer care: a survey among the members of the German Society of Hematology and Oncology. J Natl Compr Canc Netw 2013;11:658-665.

21 O'Cathain A, Thomas KJ: 'Any other comments?' Open questions on questionnaires - a bane or a bonus to research? BMC Med Res Methodol 2004;4:1-7.

22 Bankauskaite V, Saarelma O: Why are people dissatisfied with medical care services in Lithuania? A qualitative study using responses to open-ended questions. Int J Qual Health Care 2003;15:23-29.

23 Steckler A, McLeroy KR, Goodman RM, Bird ST, McCormick L: Toward integrating qualitative and quantitative methods: an introduction. Health Educ Q 1992; 19:1-8.
24 Mayring P: Qualitative content analysis. FQS 2000; 1:art 20.

25 Mayring P: Qualitative Content Analysis: Theoretical Foundation, Basic Procedures and Software Solution. Klagenfurt, 2014.

26 Mayring P: Qualitative Inhaltsanalyse: Grundlagen und Techniken. Weinheim, Beltz, 2010.

27 Ubel PA, Arnold RM: The unbearable rightness of bedside rationing. Physician duties in a climate of cost containment. Arch Intern Med 1995;155:1837-1842.

28 Fojo T, Grady C: How much is life worth: cetuximab, non-small cell lung cancer, and the $\$ 440$ billion question. J Natl Cancer Inst 2009;101:1044-1048.

29 Schnipper LE, Davidson NE, Wollins DS, Tyne C, Blayney DW, Blum D, Dicker AP, Ganz PA, Hoverman JR, Langdon R, Lyman GH, Meropol NJ, Mulvey T, Newcomer L, Peppercorn J, Polite B, Raghavan D, Rossi G, Saltz L, Schrag D, Smith TJ, Yu PP, Hudis CA, Schilsky RL; American Society of Clinical Oncology: American Society of Clinical Oncology statement: a conceptual framework to assess the value of cancer treatment options. J Clin Oncol 2015;33:2563-2577.

30 Cherny NI, Sullivan R, Dafni U, Kerst JM, Sobrero A Zielinski C, de Vries EG, Piccart MJ: A standardised, generic, validated approach to stratify the magnitude of clinical benefit that can be anticipated from anticancer therapies: the European Society for Medica Oncology Magnitude of Clinical Benefit Scale (ESMOMCBS). Ann Oncol 2015;26:1547-1573.

31 Edwards P, Roberts I, Clarke M, DiGuiseppi C, Pratap S, Wentz R, Kwan I: Increasing response rates to postal questionnaires: systematic review. BMJ 2002;324:1183. 